\title{
Role of Precautionary Measures in Containing the Natural Course of Novel Coronavirus Disease
}

This article was published in the following Dove Press journal:

Journal of Multidisciplinary Healthcare

\author{
Arwa Alumran (1D \\ Health Information Management and \\ Technology Department, College of \\ Public Health, Imam Abdulrahman Bin \\ Faisal University, Dammam, Saudi Arabia
}

Background: The coronavirus disease (COVID-19) pandemic is spreading at an alarming rate. Several health authorities have implemented specific precautionary measures worldwide to combat the spread of the disease. The influence of these measures on tackling the spread of the disease remains to be elucidated. Therefore, this study aimed to assess the impact of precautionary measures to contain the COVID-19 outbreak.

Methods: Data for this study were gathered from publicly available data sources such as the Worldometer and World Health Organization websites. The expected number of new cases is calculated using a mathematical formula to assess the difference between the observed and expected number of cases, thus indicating the impact of precautionary measures on the spread of COVID-19.

Results: The preventive measures massively impacted the reduction of COVID-19 cases in Saudi Arabia from the expected number of 437,097 accumulated cases by May 4, 2020, to the observed number of 28,656 accumulated cases. Thus, the fatality rate is reduced from the expected 15,735 accumulated deaths by May 4 to 191 accumulated deaths.

Conclusion: Precautionary measures adopted by the Saudi Arabian health authorities were evidently effective in controlling the spread and further burden of COVID-19.

Keywords: COVID-19, precautionary measures, prevention, quarantine, public health

\section{Introduction}

The coronavirus disease (COVID-19) outbreak that first occurred in China in December 2019 has become a worldwide pandemic. Several community-based recommendations have been implemented worldwide through healthcare providers. Some of the most common recommendations are social distancing, frequent handwashing, avoiding touching of the face, and wearing masks in public.

The first case of COVID-19 in Saudi Arabia was reported on March 2, 2020. Since then, several precautionary measures have been implemented by the Saudi Arabian health authorities to prevent the anticipated spread of the disease based on international forecasts about the spread of COVID-19 in different countries globally.

An outbreak has a reproductive value, which is the transmission capacity of the infecting agent. This is called $R_{0}$ ( $R$ nought). An $R_{0}$ value less than 1 indicates that the outbreak will gradually disappear. An $\mathrm{R}_{0}$ value greater than 1 indicates the need for control measures to combat the spread of an outbreak. According to Trilla, ${ }^{1}$ there is a need to exercise caution with controlling the spread of the COVID-19 outbreak.

Reporting an exact $\mathrm{R}_{0}$ of an epidemic outbreak is challenging, and several studies worldwide have attempted to estimate the reproductive value of COVID19. Zhang et $\mathrm{al}^{2}$ estimated the $\mathrm{R}_{0}$ of COVID-19 to be 2.28 (2.06-2.52). In addition,
Correspondence: Arwa Alumran Health Information Management and Technology Department, College of

Public Health, Imam Abdulrahman Bin Faisal University, P.O. Box 40I40,

Dammam 31952, Saudi Arabia

Tel +966506845783

Email aalumran@iau.edu.sa 
according to the WHO report ${ }^{3}$ in February 2020 about the early stages of the outbreak in Wuhan, the $\mathrm{R}_{0}$ of COVID19 was $2-2.5$. There have been studies that have estimated much higher $\mathrm{R}_{0}$ values; one study estimated the $\mathrm{R}_{0}$ of COVID-19 between 3.6-4.0, ${ }^{4}$ while preliminary estimation of $\mathrm{R}_{0}$ of COVID-19 in China is at ranges from 3.30 $(95 \% \mathrm{CI}=2.73-3.96)$ to $5.47 \quad(95 \% \mathrm{CI}=4.16-7.10){ }^{5}$ Because the exact assessment of $\mathrm{R}_{0}$ of COVID-19 is challenging, based on estimations from the previously mentioned studies, it is safe to say that the $R_{0}$ of COVID-19 is approximately between 3 and 4 .

The serial interval $\left(\mathrm{S}_{\mathrm{i}}\right)$ of any infection is defined by Fine $^{6}$ as "the time from illness onset in a primary case (infector) to illness onset in a secondary case (infectee)." Several studies assessed the serial interval of COVID-19; researchers in Hubei estimated the mean $\mathrm{S}_{\mathrm{i}}$ of COVID-19 to be 7.5 days. ${ }^{7}$ Another study estimated the mean $\mathrm{S}_{\mathrm{i}}$ of COVID- 19 to be 4 days. ${ }^{8}$ Determining $S_{\mathrm{i}}$ is a task as it can only be obtained by linking the date of onset from the infector to the infectee.

Once the first case of COVID-19 was confirmed in Saudi Arabia, the health authorities implemented strict precautionary measures to combat the outbreak. The first set of precautions were taken from March 2, stricter precautions from March 8, curfew started from March 25, and finally active screening of asymptomatic cases startied from April 18.

These measures started with moderately lenient methods including no Umrah, shutting down of the Holy Mosque when there were no prayers, no crowds for any sporting or recreational events, no community-based events, only take-away orders from restaurants, and crowd control in public places. Following this, more robust methods such as shutting down schools in quarantine-infected districts; discontinuing travel from or to infected countries; and suspension of international flights, mosque prayers, and domestic travel were implemented. Finally, some extreme measures were implemented, including shutting down workplaces, except those that were essential, then partial curfew (from $7 \mathrm{pm}$ or even 3 $\mathrm{pm}$ in districts with a high number of cases), then 24-hour curfew across the country, and finally active screening of asymptomatic patients. Using school buildings and hotels as quarantine areas is another method that was adopted by the Saudi Arabian health authorities to control the spread of the disease.

Active mass screening of asymptomatic subjects was carried out as part of a major campaign conducted by the
Health authorities in the country. The target of these campaigns was to relieve the spike in the cases, and thus control the epidemic from spreading further. According to the $\mathrm{MoH},{ }^{9}$ in the period of the study, from March 2 to May 1, 2020, 364,561 cases were screened.

Available data on the impact of precautionary measures on the spread of COVID-19 is scarce. This study is an attempt by the author to assess the impact of precautionary measures to contain the COVID-19 outbreak, thus reducing the mortality rates in Saudi Arabia. It is important to note that assessing the financial burden of these measures is outside the scope of this article.

\section{Methods}

Publicly available information about the number of new cases, the number of recovered cases, and the number of deaths in Saudi Arabia was gathered from the COVID19 dashboard provided by the Saudi Ministry of Health website $\mathrm{MoH}^{9}$ and from WorldMeter. ${ }^{10}$

Precautionary measures in Saudi Arabia were collected and followed up through local newspapers and official announcements. The expected number of cases and case fatality rate are calculated using the estimated $\mathrm{R}_{0}$ of COVID-19. As the pandemic continues to grow beyond the data collection date (May 1, 2020), the expected number of cases (without precautionary measures) is expected to increase.

There are many estimations of the $\mathrm{S}_{\mathrm{i}}$ of COVID-19, as previously mentioned. For the sake of this study and to be more conservative in the calculations, the $\mathrm{S}_{\mathrm{i}}$ in the mathematical formula was set to 6 days. Owing to the debate regarding the appropriate $\mathrm{R}_{0}$ estimation of COVID-19, as previously mentioned, an $\mathrm{R}_{0}$ of 2.5 was used to calculate the expected spread of the infection in Saudi Arabia. The mathematical formula that was used in the study is:

$$
N=\sum_{m=59}^{m=1} n(m+6)=[n(m) \times R 0]+n(m)
$$

where $N$ is the total number of expected cases at the time when the study ended, $m$ indicates the day number, and $n$ indicates the number of expected cases per day.

The expected number of deaths from COVID-19 in Saudi Arabia is calculated using the international estimation of the death rate of COVID-19, that is $3.6 \% .{ }^{11}$ The international case fatality rate of COVID-19 is set regardless of the influencing comorbidities and age distribution of the population. 


\section{Results}

The first case of COVID-19 in Saudi Arabia was reported on March 2, 2020. This was followed by a series of cases in the following days. The population estimation of the Kingdom of Saudi Arabia in 2020 is 34,713,236, according to the General Authority for Statistics. ${ }^{12}$

Table 1 shows the accumulated observed number of cases and the accumulated expected number of cases at each precautionary measure implementation stage. Further, the total number of observed deaths from COVID-19 as well as the expected number of deaths is shown in Table 1.

Figure 1 depicts the exponential curve that shows the expected number of cases if precautionary measures were not implemented in Saudi Arabia. Figure 2 shows the exponential expected growth in terms of the number of deaths from COVID-19 if precautionary measures were not implemented.

One of the first measures implemented by the Saudi Arabian health authorities was a travel ban, crowd control, and social distancing on March 2, 2020. Following this, more extreme measures were adopted by the Saudi Arabian health authorities on March 8, such as sealing specific geographical locations with a large number of infected cases and shutting down schools and workplaces. Further, extreme measures followed at later stages from March 25, including partial (until 3 or $7 \mathrm{pm}$ ) and 24-hour curfews. The last measure implemented by the health authorities in Saudi Arabia was the active screening of individuals in specific neighborhoods, which started on April 18.

The number of COVID-19 cases in Saudi Arabia was expected to reach 258,283 cases by May 1, 2020 (ie, within 2 months of the onset of outbreak in Saudi Arabia) if precautionary measures had not been implemented in the country. This number is predicted according to the internationally estimated $\mathrm{R}_{0}$ of COVID-19. The total number of deaths was expected to reach almost 9000 by May 1, 2020, according to the international case fatality rate of COVID-19. As shown in Table 1, since the start of active screening by the Saudi Arabian health authorities, the number of new cases increased at an alarming rate.

\section{Discussion}

To the author's knowledge, this is the first study to assess the impact of precautionary measures in Saudi Arabia on combating a pandemic. The study resulted in interesting findings that support the huge impact of precautionary measures during a pandemic outbreak. The number of new cases in Saudi Arabia drastically reduced after the implementation of extreme precautionary measures.

Similar to this study's results, a study in Italy highlights the importance of country lockdown in controlling the spread of the disease. ${ }^{13}$ Country lockdown is one of the extreme measures adopted by the Saudi Arabian health

Table I Number of Observed vs Expected Cases of COVID-19 in Saudi Arabia at Each Precautionary Measure Stage

\begin{tabular}{|c|c|c|c|c|c|c|c|c|}
\hline \multirow[t]{2}{*}{ Day } & \multirow[t]{2}{*}{ Date } & \multirow[t]{2}{*}{$\begin{array}{l}\text { Precautionary } \\
\text { Measure }\end{array}$} & \multirow[t]{2}{*}{$\begin{array}{l}\text { Susceptible } \\
\text { Population }\end{array}$} & \multicolumn{2}{|c|}{$\begin{array}{l}\text { Cumulative COVID- } \\
\text { I } 9 \text { Positive Cases }\end{array}$} & \multicolumn{2}{|c|}{$\begin{array}{l}\text { Cumulative Number } \\
\text { of Relevant Mortality }\end{array}$} & \multirow[t]{2}{*}{$\begin{array}{l}\text { Cumulative } \\
\text { Observed Recovered }\end{array}$} \\
\hline & & & & Observed & Expected & Observed & Expected & \\
\hline I & Mar 2 & No travel & $34,7 \mid 3,235$ & 1 & 1.00 & 0 & 0.03 & 0 \\
\hline 4 & Mar 5 & Social distancing & $34,7 \mid 3,233$ & 5 & 4.00 & 0 & 0.14 & I \\
\hline 6 & Mar 7 & No crowding & $34,7 \mid 3,234$ & 7 & 7.50 & 0 & 0.26 & 1 \\
\hline 7 & Mar 8 & $\begin{array}{l}\text { Quarantine infected } \\
\text { areas }\end{array}$ & $34,7 \mid 3,232$ & 11 & 10.00 & 0 & 0.34 & 1 \\
\hline 8 & Mar 9 & Schools shut down & $34,7 \mid 3,232$ & 15 & 12.50 & 0 & 0.43 & I \\
\hline 14 & Mar 15 & $\begin{array}{l}\text { Governmental } \\
\text { workplaces shut down }\end{array}$ & $34,7|3,22|$ & 118 & 42.50 & 0 & 1.45 & I \\
\hline 17 & Mar 18 & $\begin{array}{l}\text { Private workplaces shut } \\
\text { down }\end{array}$ & $34,713,169$ & 238 & 80.00 & 0 & 2.72 & 6 \\
\hline 24 & Mar 25 & Partial curfew & $34,7 \mid 3,103$ & 900 & 283.13 & 2 & 9.63 & 29 \\
\hline 37 & Apr 7 & 24-hour curfew & $34,7 \mid 2,964$ & 2795 & 3251.88 & 41 & 110.56 & 615 \\
\hline 48 & Apr 18 & Active screening & $34,7 \mid 2,104$ & 8274 & $24,156.42$ & 92 & 821.32 & 1329 \\
\hline 60 & Apr 30 & Active screening & $34,7 \mid 3,236$ & 21,402 & $198,678.82$ & 157 & 6755.08 & 3163 \\
\hline 64 & May 4 & Active screening & $34,7 \mid 1,591$ & 28,656 & $59,604.64$ & 191 & $|5,735.5|$ & 4476 \\
\hline
\end{tabular}




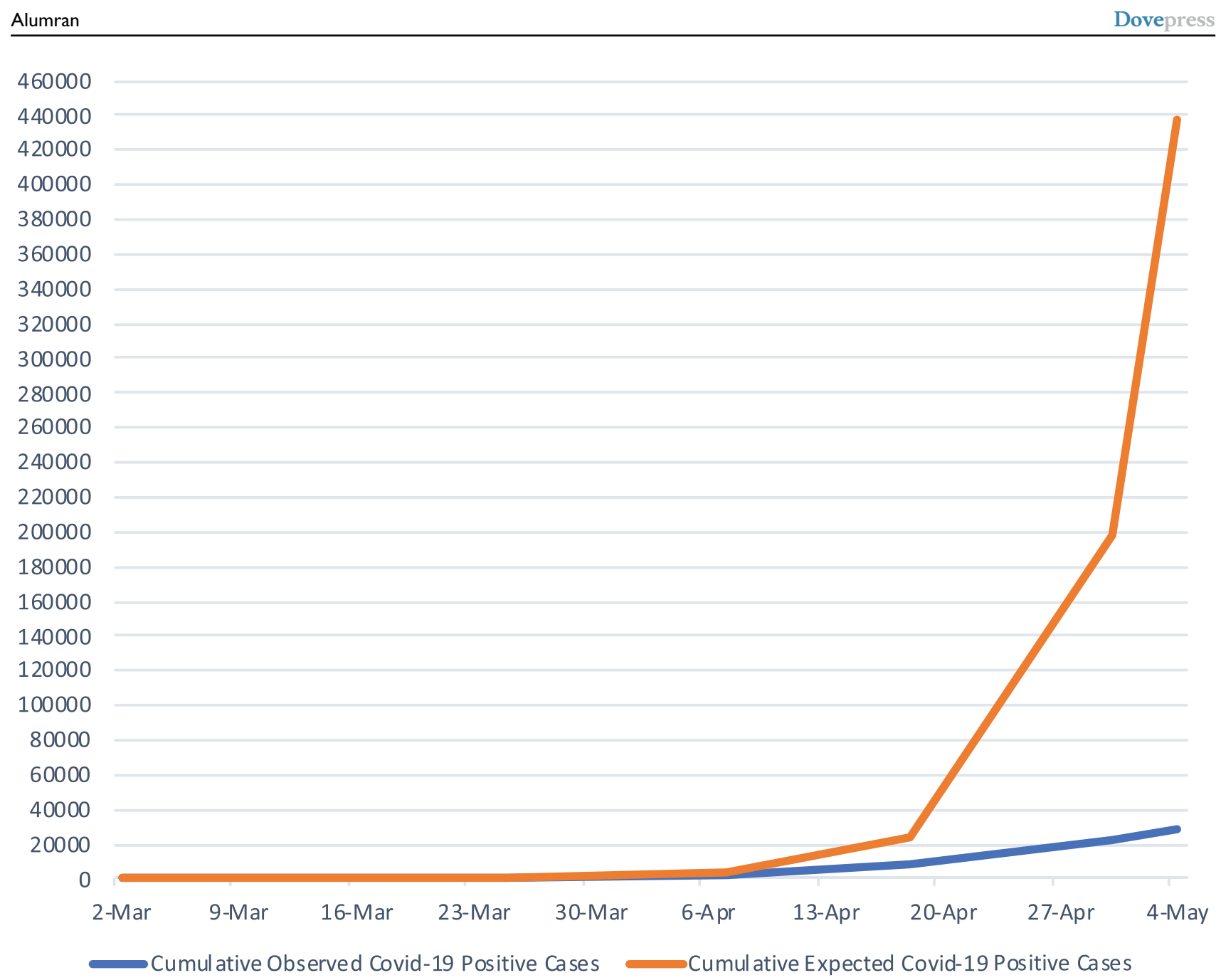

Figure I Number of observed vs expected coronavirus disease cases in Saudi Arabia.

authorities to control the spread of the disease. Evidently, this is one of the most effective measures to combat an outbreak.

Dowd et $\mathrm{al}^{14}$ believe that governments worldwide must adopt strict precautionary measures to mitigate the COVID-19 pandemic. This is also advocated by Li et al, ${ }^{7}$ who believe that preventive measures need to be implemented for populations at risk. A study forecasting the outbreak of COVID-19 in India indicated that if the outbreak is not controlled within a short period of time, India will face severe shortage of healthcare settings, which will worsen the impact of the outbreak. ${ }^{15}$

A study conducted in Hong Kong in 2003 regarding the effectiveness of precautions against contaminated droplet-induced infection and contact with an infected person in the prevention of nosocomial transmission of severe acute respiratory syndrome found that precautions such as using masks and other practices to prevent droplet infection significantly reduce exposure to the virus. ${ }^{16}$ This is consistent with the findings of the current study, where social isolation played a favorable role in the control of further spread of COVID-19 in Saudi Arabia.

Awareness campaigns are one of the most important precautionary measures adapted by the Saudi health authorities since the onset of the epidemic in the country. According to Roy et al, ${ }^{17}$ public's awareness influences their adherence to precautionary measures and eventually the clinical outcome. With a lack of awareness people may violate the quarantine or any other precautionary measure by behaving irresponsibly which will eventually have a negative impact on their health. ${ }^{18}$

It is important to note that Saudi Arabia adopted an out-reach program to screen susceptible asymptomatic patients, in contrast to other countries where positive cases reflect testing of only symptomatic patients. The 


\section{Obsevered vs. expected number of deaths from Covid19 in Saudi Arabia}

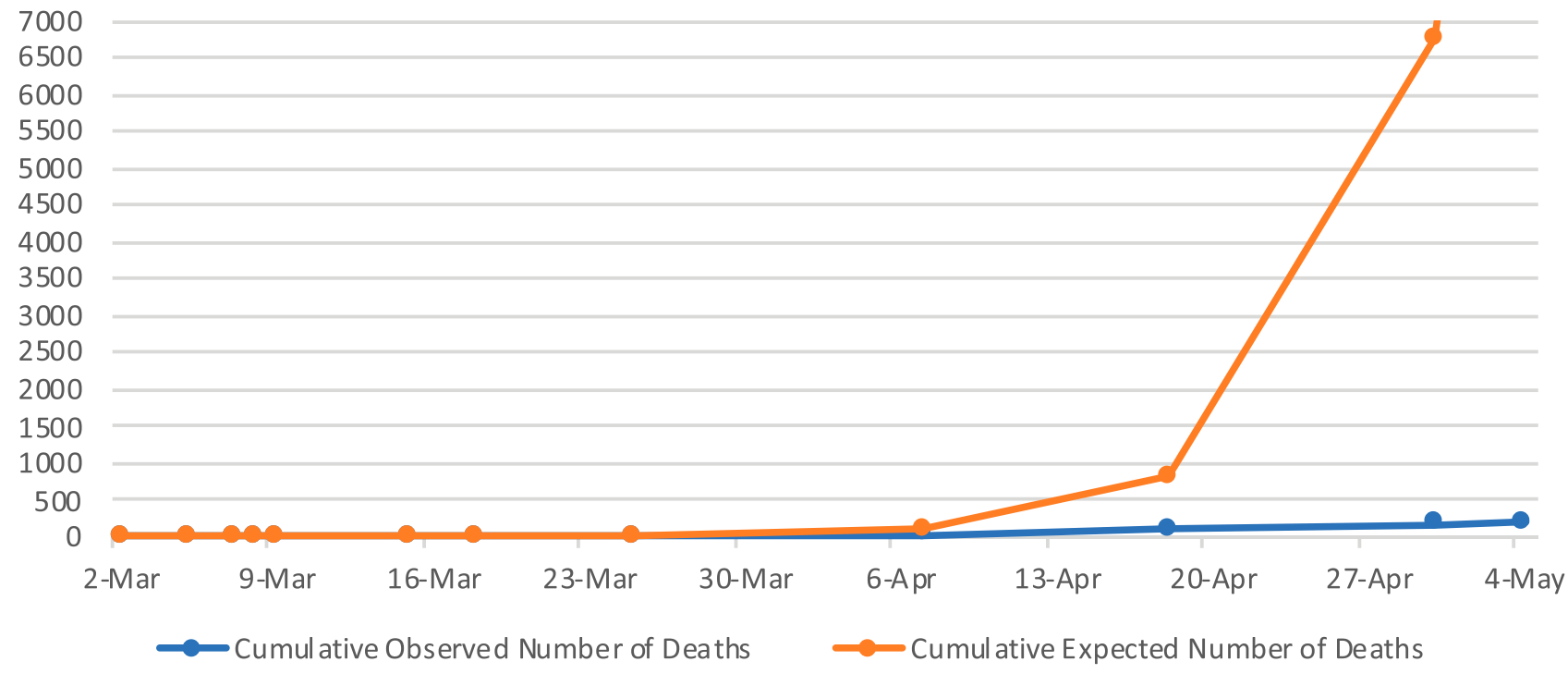

Figure 2 Observed vs expected number of deaths from coronavirus disease in Saudi Arabia.

total number of screened cases in Saudi Arabia is 364,561 cases. ${ }^{9}$ This is one of the most effective methods for combating the spread in the earlier stages.

The age-distribution of the community has a significant impact on the case fatality rate of COVID-19. For instance, a higher burden of mortality is more apparent in countries with a higher percentage of older population. ${ }^{14}$ The median age in Saudi Arabia is 31.8 years. ${ }^{12}$ This should be taken into consideration when estimating the relevant case fatality rate of COVID-19 in Saudi Arabia; however, age distribution in Saudi Arabia is not taken into consideration when estimating the expected number of cases of COVID-19 or the relevant mortality rate.

Lastly, it is worth mentioning that, as the data used in the study is from governmental sources, there was no stratification of cases by gender, age group, or any other demographic characteristics.

\section{Conclusion}

The COVID-19 pandemic can be controlled if extreme precautionary measures are implemented in the earlier stages of the outbreak in a country. The Kingdom of Saudi Arabia adopted several precautionary measures to contain the spread of COVID-19, starting with some lenient measures and ending with extreme measures and active screening of the population.
This is the first study to measure the impact of precautionary measures on combating the spread of a pandemic in Saudi Arabia. The spread of COVID-19 has been controlled in Saudi Arabia after implementing several preventive measures. The daily number of newly confirmed cases in Saudi Arabia is extremely low after implementing these measures compared with other countries with a similar population, such as Spain, Canada, and Peru. Thus, the mortality rate of the pandemic has also been reduced in Saudi Arabia.

\section{Acknowledgment}

I would like to thank Editage for English language editing.

\section{Funding}

This research did not receive any specific grant from funding agencies in the public, commercial, or not-forprofit sectors.

\section{Disclosure}

The author reports no conflicts of interest in this work.

\section{References}

1. Trilla A. One world, one health: the novel coronavirus COVID-19 epidemic. Med Clin (Barc). 2020;154(5):175-177. doi:10.1016/j. medcli.2020.02.002 
2. Zhang S, Diao M, Yu W, Pei L, Lin Z, Chen D. Estimation of the reproductive number of novel coronavirus (COVID-19) and the probable outbreak size on the Diamond Princess cruise ship: a data-driven analysis. Int $J$ Infect Dis. 2020;93(1):201-204. doi:10.1016/j. ijid.2020.02.033

3. WHO, W. H. O. Report of the WHO-China Joint Mission on Coronavirus Disease 2019 (COVID-19); 2020. Available from: https:/www.who.int/docs/default-source/coronaviruse/who-chinajoint-mission-on-covid-19-final-report.pdf. Accessed July 9, 2020

4. Distante C, Piscitelli P, Miani A. Covid-19 outbreak progression in italian regions: approaching the peak by March 29th. medRxiv. 2020. doi:10.1101/2020.03.30.20043612

5. Zhao S, Ran J, Musa SS, et al. Preliminary estimation of the basic reproduction number of novel coronavirus $(2019-\mathrm{nCoV})$ in China, from 2019 to 2020: a data-driven analysis in the early phase of the outbreak. Int J Infect Dis. 2020;92:214-7.

6. Fine PE. The interval between successive cases of an infectious disease. Am J Epidemiol. 2003;158(1):1039-1047. doi:10.1093/aje/ kwg251

7. Li Q, Guan X, Wu P, et al. Early transmission dynamics in Wuhan, China, of novel coronavirus-infected pneumonia. $N$ Engl J Med. 2020;382(13):1199-1207. doi:10.1056/NEJMoa2001316

8. Nishiuraa H, Lintona N, Akhmetzhanov A. Serial interval of novel coronavirus (COVID-19) infections. Int $J$ Infect Dis. 2020;93 (1):284-286. doi:10.1016/j.ijid.2020.02.060

9. MoH MOH. COVID 19 Dashboard: saudi Arabia; 2020. Available from: https://covid19.moh.gov.sa. Accessed July 9, 2020.

10. WorldMeter. COVID-19 CORONAVIRUS PANDEMIC; April 29, 2020. Available from: https://www.worldometers.info/coronavirus/. Accessed July 9, 2020.
11. Baud D, Qi X, Nielsen-Saines K, Musso D, Pomar L, Favre G. Real estimates of mortality following COVID-19 infection. Lancet Infect Dis. 2020;2020. doi:10.1016/S1473-3099(20)30195-X.

12. General Authority for Statistics, K. o. S. A. Saudi Census. May 1, 2020 Available from: https://www.stats.gov.sa/en. Accessed July 9, 2020 .

13. Chintalapudi N, Battineni G, Amenta F. COVID-19 virus outbreak forecasting of registered and recovered cases after sixty day lockdown in Italy: a data driven model approach. $J$ Microbiol Immunol Infect. 2020;53(3):396-403. doi:10.1016/j.jmii.2020.04.004

14. Dowd JB, Andriano L, Brazel DM, et al. Demographic science aids in understanding the spread and fatality rates of COVID-19. Proc Natl Acad Sci U S A. 2020;117(18):9696-9698. doi:10.1073/ pnas.2004911117

15. Tiwari S, Kumar S, Guleria K. Outbreak trends of CoronaVirus (COVID-19) in India: a prediction. Disaster Med Public Health Prep. 2020;22:1-9. doi:10.1017/dmp.2020.115

16. Seto W, Tsang D, Yung R, et al. Effectiveness of precautions against droplets and contact in prevention of nosocomial transmission of severe acute respiratory syndrome (SARS). Lancet. 2003;361:15191520. doi:10.1016/S0140-6736(03)13168-6

17. Roy D, Tripathy S, Kar SK, Sharma N, Verma SK, Kaushal V. Study of knowledge, attitude, anxiety \& perceived mental healthcare need in Indian population during COVID-19 pandemic. Asian J Psychiatr. 2020;51(1):102083. doi:10.1016/j.ajp.2020.102083

18. Roy D, Sinha K. Cognitive biases operating behind the rejection of government safety advisories during COVID19 pandemic. Asian J Psychiatr. 2020;51(1):102048. doi:10.1016/j.ajp.2020.102048
Journal of Multidisciplinary Healthcare

\section{Publish your work in this journal}

The Journal of Multidisciplinary Healthcare is an international, peerreviewed open-access journal that aims to represent and publish research in healthcare areas delivered by practitioners of different disciplines. This includes studies and reviews conducted by multidisciplinary teams as well as research which evaluates the results or conduct of such teams or healthcare processes in general. The journal

\section{Dovepress}

covers a very wide range of areas and welcomes submissions from practitioners at all levels, from all over the world. The manuscript management system is completely online and includes a very quick and fair peer-review system. Visit http://www.dovepress.com/testimonials. php to read real quotes from published authors. 